Check for updates

Cite this: RSC Adv., 2018, 8, 27073

\title{
Flake-like $\mathrm{InVO}_{4}$ modified $\mathrm{TiO}_{2}$ nanofibers with longer carrier lifetimes for visible-light photocatalysts
}

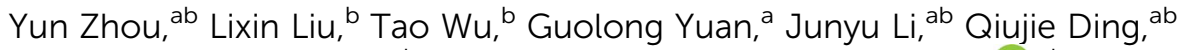 \\ Fugang $\mathrm{Qi}^{a}{ }^{a}$ Wenjun Zhu, ${ }^{\mathrm{b}}$ Xiaoping OuYang ${ }^{\star a}$ and Yuan Wang (D) ${ }^{* b}$
}

\begin{abstract}
Highly efficient solar light absorption capabilities and quantum yields in photocatalysts are key to their application in photocatalytic fields. Towards this end, $\mathrm{TiO}_{2} / \mathrm{InVO}_{4}$ nanofibers (NFs) have been designed and fabricated successfully by a one-pot electrospinning process. The resulting $\mathrm{TiO}_{2} / \mathrm{InVO}_{4} \mathrm{NFs}$ display excellent visible-light photocatalytic activity, owing to their prominent visible-light absorption and electron-hole separation properties. Time-resolved transient PL spectroscopy demonstrated that the $\mathrm{TiO}_{2} / \mathrm{InVO}_{4} \mathrm{NFs}$ display longer emission decay times (22.0 ns) compared with $\mathrm{TiO}_{2} \mathrm{NFs}(15.5 \mathrm{~ns})$, implying that the heterojunction can remarkably suppress the electron-hole recombination and promote the carrier transfer efficiency. With tailored heterostructure features, $\mathrm{TiO}_{2} / \mathrm{InVO}_{4} \mathrm{NFs}_{\text {s }}$ exhibit superior visible-light photodegradation activity, and after $80 \mathrm{~min}$ of visible-light irradiation, almost $95 \%$ of RhB molecules can be decomposed by $\mathrm{TiO}_{2} / \mathrm{InVO}_{4} \mathrm{NFs}$, while only $18 \%$ of RhB molecules can be decomposed by pure $\mathrm{TiO}_{2} \mathrm{NFs}$
\end{abstract}

Received 22nd May 2018

Accepted 23rd July 2018

DOI: $10.1039 / \mathrm{c} 8 \mathrm{ra} 04344 \mathrm{~b}$

rsc.li/rsc-advances

constructing a $\mathrm{TiO}_{2}$-based semiconductor/semiconductor

\section{Introduction}

Nowadays, with the overuse of various dyes and plastic products, organic pollutants in water and soil have drawn increasing attention. Among the various strategies, the development of efficient photocatalysts is a promising method for the treatment of organic pollutants, owing to its utilization of abundant solar energy, as well as its low cost and lack of secondary pollution during the course of decomposition. ${ }^{1-3}$ Since A. Fujishima discovered the interesting phenomenon of light-induced water splitting by $\mathrm{TiO}_{2}$ in the $1970 \mathrm{~s},{ }^{4} \mathrm{TiO}_{2}$ materials have been the most promising candidates for photocatalytic decontamination on account of their non-toxic, non-luminous corrosion, inert chemical properties, high photocatalytic activity, low cost, and cycle stability. ${ }^{5-7}$ However, further application of $\mathrm{TiO}_{2}$ photocatalysts is unfortunately limited by their large bandgap energy and short photogenerated carrier lifetimes. ${ }^{8}$ To overcome these limitations, persistent research, such as non-metal element or metal ion doping, ${ }^{9-11}$ surface modification, ${ }^{12}$ semiconductor/ metal combination, ${ }^{13,14}$ and semiconductor/semiconductor hybridization, ${ }^{15-17}$ has been engaged in order to narrow the bandgap energy for better visible-light absorption and promote electron-hole separation for longer carrier lifetimes. Herein,

${ }^{a}$ School of Materials Science and Engineering, Xiangtan University, Xiangtan 411105, Hunan, China. E-mail: oyxp2003@alyun.com

${ }^{b}$ National Key Laboratory for Shock Wave and Detonation Physics, Institute of Fluid Physics, China Academy of Engineering Physics, P.O. Box 919-111, Mianyang, Sichuan 621900, People's Republic of China. E-mail: wangyuan0000@gmail.com nanoheterostructured photocatalyst is an efficient method to increase visible-light harvesting and meanwhile suppress electron-hole recombination, ultimately leading to photocatalytic activity improvement. ${ }^{18}$ Up until now, many $\mathrm{TiO}_{2}$-based nanoheterostructures with excellent photocatalytic performance have been reported, such as $\mathrm{TiO}_{2} / \mathrm{SnO}_{2},{ }^{19} \mathrm{TiO}_{2} / \mathrm{ZnO},{ }^{20} \mathrm{TiO}_{2} /$ $\mathrm{CdS},{ }^{21} \mathrm{TiO}_{2} / \mathrm{MoS}_{2},{ }^{22} \mathrm{TiO}_{2} / \mathrm{g}^{-} \mathrm{C}_{3} \mathrm{~N}_{4}{ }^{23} \mathrm{TiO}_{2} / \mathrm{CuInS}_{2},{ }^{24}$ etc. Therefore, designing and constructing impactful nanoheterostructures is an effectual way to extend the lifetime of the photogenerated charge, and consequently improve the photocatalytic activity.

$\mathrm{InVO}_{4}$ semiconductors, as an important group of semiconductors, have attracted much interest because of their potential applications in visible-light-driven photocatalysis, photoelectrochemistry, and gas sensing. ${ }^{25,26}$ In particular, $\mathrm{InVO}_{4}$ is considered to be an ideal choice for coupling with $\mathrm{TiO}_{2}$ to improve the visible-light photocatalytic performance due to its relatively low bandgap energy $\left(E_{\mathrm{g}} \approx 2.1 \mathrm{eV}\right)$ and energy level matching with $\mathrm{TiO}_{2}$. Up till now, the process for fabricating $\mathrm{TiO}_{2} / \mathrm{InVO}_{4} \mathrm{NFs}$ usually involves a few synthesis steps, including loading $\mathrm{TiO}_{2}$ or $\mathrm{InVO}_{4}$ particles on the surface of $\mathrm{InVO}_{4}$ or $\mathrm{TiO}_{2}$, such as via a hydrothermal method followed by an ion impregnate method. ${ }^{27-29}$ Hence, the fabrication method for $\mathrm{TiO}_{2} / \mathrm{InVO}_{4}$ nanoheterostructures needs to be simplified. Furthermore, although previous research has revealed that $\mathrm{TiO}_{2} / \mathrm{InVO}_{4}$ heterostructures exhibit enhanced UV-Vis and visible-light photocatalytic performance, in-depth analysis of the charge transfer and carrier lifetimes of the nanoheterostructure is still missing. For example, Ge et al. explored 
the visible-light photocatalytic performance of an $\mathrm{InVO}_{4}-\mathrm{TiO}_{2}$ photocatalyst synthesized by a sol-gel method, whereas further discussion on the photocatalytic improvement mechanism is absent. ${ }^{30}$ Shen and Perales-Martínez proposed a mechanism for the electron-hole separation process in $\mathrm{TiO}_{2} / \mathrm{InVO}_{4}$ composites only based on the energy band structure, without intuitive experimental characterization. ${ }^{27,28}$ Thus, it is necessary to further study the charge transfer and lifetime of the photogenerated charges of $\mathrm{TiO}_{2} / \mathrm{InVO}_{4}$ composites, and it should be clarified as to how much the heterojunction contributes to electron transport, and for how long the carrier lifetime can be obtained through separation at the interface of the heterojunction. Hence, the charge transfer mechanism and carrier lifetime of $\mathrm{TiO}_{2} / \mathrm{InVO}_{4}$ nanoheterostructures need to be analyzed in-depth.

In this paper, we successfully synthesized $\mathrm{TiO}_{2} / \mathrm{InVO}_{4} \mathrm{NFs}$ by a one-pot electrospinning method for the first time, which could provide ample heterojunction interfaces as separation channels for photogenerated electron-hole pairs. Moreover, time-resolved transient PL spectroscopy was employed to confirm the carrier lifetime of the $\mathrm{TiO}_{2} / \mathrm{InVO}_{4} \mathrm{NFs}$. With the tailored nanoheterostructures, the prepared $\mathrm{TiO}_{2} / \mathrm{InVO}_{4} \mathrm{NFs}$ exhibited enhanced photocatalytic activity due to broadened visible-light harvesting and efficiently prolonged carrier lifetimes resulting from the nanoheterojunction formed between $\mathrm{TiO}_{2}$ and $\mathrm{InVO}_{4}$.

\section{Materials and methods}

\subsection{Synthesis of $\mathrm{TiO}_{2} / \mathrm{InVO}_{4} \mathrm{NFs}$}

$\mathrm{TiO}_{2} / \mathrm{InVO}_{4}$ NFs were synthesized by a one-pot electrospinning process, as shown in Fig. 1 (a). Briefly, $0.19 \mathrm{~g} \mathrm{In}\left(\mathrm{NO}_{3}\right)_{3} \cdot 4.5 \mathrm{H}_{2} \mathrm{O}$, $0.18 \mathrm{~g} \mathrm{VO}(\mathrm{acac})_{2}, 0.68 \mathrm{~g}$ tetrabutyl titanate (TBT), and $0.4 \mathrm{~g}$ polyvinylpyrrolidone (PVP) were added into a mixed solution of $2 \mathrm{~g}$ dimethylacetamide (DMAC), $1.0 \mathrm{ml}$ ethanol, and $0.8 \mathrm{ml}$ acetic acid, after which the above solution was magnetically stirred for $30 \mathrm{~min}$, and thus an $\operatorname{In}\left(\mathrm{NO}_{3}\right)_{3} / \mathrm{VO}(\mathrm{acac})_{2} / \mathrm{TBT} / \mathrm{PVP}$ mixed solution with a Ti/In molar ratio of $4: 1$ was obtained. Then, the mixed solution was electrospun to compose the In $\left(\mathrm{NO}_{3}\right)_{3} / \mathrm{VO}(\mathrm{acac})_{2} / \mathrm{TBT} / \mathrm{PVP}$ NFs. The electrospinning parameters were set as follows: $0.4 \mathrm{~mm}$ for the inner diameter of the spinneret, and $20 \mathrm{~cm}$ and $15 \mathrm{kV}$ for the distance and DC voltage between the spinneret and the collector, respectively. Finally, the obtained NFs were annealed at $550{ }^{\circ} \mathrm{C}$ for $2 \mathrm{~h}$ in air to remove the PVP support and crystallise the $\mathrm{TiO}_{2} / \mathrm{InVO}_{4} \mathrm{NFs}$. A comparative sample of $\mathrm{TiO}_{2}$ NFs was also synthesized by the same electrospinning method with a solution of $0.68 \mathrm{~g}$ tetrabutyl titanate (TBT) and $0.14 \mathrm{~g}$ polyvinylpyrrolidone (PVP) in a mixed solution of $1.0 \mathrm{ml}$ ethanol and $0.8 \mathrm{ml}$ acetic acid.

\subsection{Photochemical experiments}

The visible-light photocatalytic activity of the nanofibers was measured from the degradation of Rhodamine $\mathrm{B}(\mathrm{RhB})$

(a)
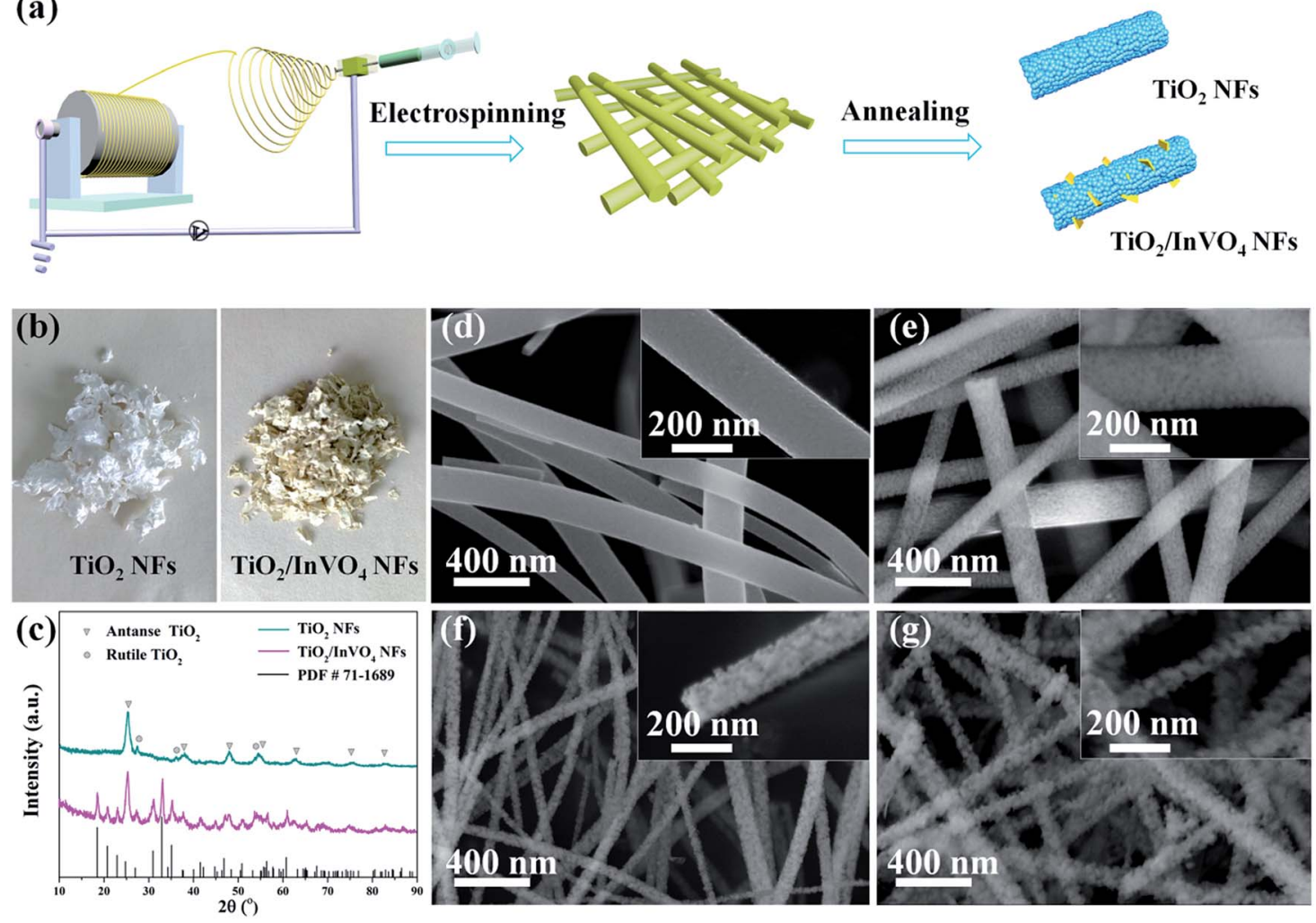

Fig. 1 (a) Schematic illustration of the fabrication process for the $\mathrm{TiO}_{2} \mathrm{NFs}_{\text {and }} \mathrm{TiO}_{2} / \mathrm{InVO}_{4} \mathrm{NFs}$. (b) Physical pictures and (c) XRD patterns of the $\mathrm{TiO}_{2} \mathrm{NFs}$ and $\mathrm{TiO}_{2} / \mathrm{InVO}_{4} \mathrm{NFs}(\mathrm{Ti} / \mathrm{In}=4: 1)$. (d-g) SEM images of (d) the $\mathrm{TiO}_{2} \mathrm{NFs}$ and $(\mathrm{e}-\mathrm{g}) \mathrm{TiO}_{2} / \mathrm{InVO}_{4} \mathrm{NFs}$ with Ti/ln molar ratios of $8: 1,4: 1$, $2: 1$, respectively. 
molecules. Firstly, $50 \mathrm{mg}$ catalysts were added to $30 \mathrm{ml} \mathrm{RhB}$ (10 $\mathrm{mg} \mathrm{l}^{-1}$ ) solution and the suspensions were placed in dark environment for $30 \mathrm{~min}$ to reach an equilibrium of absorption and desorption. Secondly, a Xe lamp $(\lambda>420 \mathrm{~nm})$ was employed for visible-light photocatalytic irradiation. At time intervals of $10 \mathrm{~min}, 3 \mathrm{ml}$ suspensions were sucked and filtered to separate the catalysts. The variations in the filtrates were assessed using the change in the absorption band maximum recorded using a TU-1901 spectrophotometer.

\subsection{Characterization}

X-ray diffraction (XRD, X'pert Pro, $\mathrm{CuK} \alpha, \lambda=1.5406$ ) and highresolution transmission electron microscopy (HRTEM, Libra 200FE) were utilized to characterize the crystal structure of the nanofibers. Energy dispersive spectroscopy (EDS) and X-ray photoelectron spectroscopy (XPS) were employed to characterize the components of the samples. The morphologies of the nanofibers were obtained by Field emission scanning electron microscopy (FESEM, Hitachi S-4800) and TEM. Nitrogen adsorption-desorption isotherms (JW-BK122 W nitrogen adsorption apparatus) were used to evaluate the BrunauerEmmett-Teller (BET) specific surface areas of the nanofibers. Furthermore, UV-Vis absorption spectra were obtained using a UV-3150 spectrophotometer, and photoluminescence (PL) spectra were obtained using a Raman spectrometer with a $532 \mathrm{~nm}$ laser excitation source. Transient PL curves for the nanofibers were recorded using a FLS920 fluorescence lifetime spectrophotometer (Edinburgh Instruments, UK) with the excitation wavelength at $532 \mathrm{~nm}$.

\section{Results and discussion}

$\mathrm{TiO}_{2} / \mathrm{InVO}_{4}$ NFs were synthesized by a one-pot electrospinning process, as shown in Fig. 1(a). Physical pictures of the samples are displayed in Fig. 1(b). It is quite distinct that the color of the $\mathrm{TiO}_{2}$ NFs is white, while the $\mathrm{TiO}_{2} / \mathrm{InVO}_{4}$ NFs appear to be faint yellow. Furthermore, XRD patterns are employed to characterize the phase composition of the resulting $\mathrm{TiO}_{2} / \mathrm{InVO}_{4} \mathrm{NFs}$, with the $\mathrm{TiO}_{2}$ NFs as a reference sample, as presented in Fig. 1(c). The diffraction peaks of the $\mathrm{TiO}_{2}$ NFs can be indexed to anatase $\mathrm{TiO}_{2}$ (PDF \#21-1272) and rutile $\mathrm{TiO}_{2}$ (PDF \#21-1276). In the case of the $\mathrm{TiO}_{2} / \mathrm{InVO}_{4} \mathrm{NFs}$, a superimposed XRD pattern of $\mathrm{TiO}_{2}$ and orthorhombic $\mathrm{InVO}_{4}$ (PDF \#71-1689) is observed, which demonstrates both $\mathrm{TiO}_{2}$ and $\mathrm{InVO}_{4}$ with good crystallization in the $\mathrm{TiO}_{2} / \mathrm{InVO}_{4}$ NFs.

The general morphologies of the nanofibers are obtained from SEM images and the results are demonstrated in Fig. 1(d), in which it is clearly revealed that one-dimensional $\mathrm{TiO}_{2}$ and $\mathrm{TiO}_{2} / \mathrm{InVO}_{4}$ structures have been successfully constructed. As shown in Fig. 1(d), the $\mathrm{TiO}_{2}$ NFs have rough and uniform morphologies, with average diameters of about $150 \mathrm{~nm}$ and lengths of about a few micrometers. The morphologies of the $\mathrm{TiO}_{2} / \mathrm{InVO}_{4}$ NFs with different $\mathrm{Ti} / \mathrm{In}$ molar ratios are presented in Fig. 1(e-g), which all have an average length of a few micrometers, as well as loose and rough surfaces. Furthermore, with a decrease in the Ti/In molar ratio, it is obvious that the average diameter of the $\mathrm{TiO}_{2} / \mathrm{InVO}_{4}$ NFs decreases and the surface of the $\mathrm{TiO}_{2} / \mathrm{InVO}_{4}$ NFs becomes much more loose and rough, which can be attributed to the adjustment of the PVP amount and the epitaxial growth of $\mathrm{InVO}_{4}$ in the electrospinning process.

To further confirm the microscopic morphologies and crystal structures of the $\mathrm{TiO}_{2} / \mathrm{InVO}_{4}$ NFs, TEM images are recorded in Fig. 2. It is obvious that the $\mathrm{TiO}_{2} / \mathrm{InVO}_{4} \mathrm{NFs}$ with a diameter of $\sim 100 \mathrm{~nm}$ (Fig. 2(a)) are composed of many distinct crystal particles and flakes, as displayed in Fig. 2(b). Then, we obtained an HRTEM image of the $\mathrm{TiO}_{2} / \mathrm{InVO}_{4}$ NFs to further observe the distributional crystal particles, and the result is presented in Fig. 2(c). The lattice distance of $0.35 \mathrm{~nm}$ is attributed to the (101) lattice distance of anatase $\mathrm{TiO}_{2}$, and the measured lattice fringes of $0.28 \mathrm{~nm}$ and $0.36 \mathrm{~nm}$ correspond to the interplanar spacings of the (200) and (021) planes of orthorhombic $\mathrm{InVO}_{4}$, respectively, indicating that the $\mathrm{TiO}_{2} /$ $\mathrm{InVO}_{4}$ nanoheterostructures have been prepared successfully. Additionally, the results of the STEM-EDS elemental mapping analysis are displayed in Fig. 2(d-g) to further explore the element distributions in the $\mathrm{TiO}_{2} / \mathrm{InVO}_{4}$ nanofibers. It is obvious that the $\mathrm{TiO}_{2} / \mathrm{InVO}_{4}$ nanofibers are mainly composed of the metals $\mathrm{Ti}$, In, and $\mathrm{V}$, and the diameters of In and $\mathrm{V}$ are larger than that of $\mathrm{Ti}$, which indicates that the flake-structure on the surfaces of the $\mathrm{TiO}_{2} / \mathrm{InVO}_{4}$ NFs can be assigned to the secondary growth of $\mathrm{InVO}_{4}$.

In order to further determine the molar ratio of elements in all the $\mathrm{TiO}_{2} / \mathrm{InVO}_{4} \mathrm{NFs}$ ( $\mathrm{Ti} / \mathrm{In}=4: 1$ ), energy dispersive spectroscopic (EDS) analysis was applied and the results are shown in Fig. 3, in which it can be observed that Ti, In, V, and $\mathrm{O}$ appear in the $\mathrm{TiO}_{2} / \mathrm{InVO}_{4} \mathrm{NFs}$, and the atomic ratios of $\mathrm{Ti}$, In, and $\mathrm{V}$ are

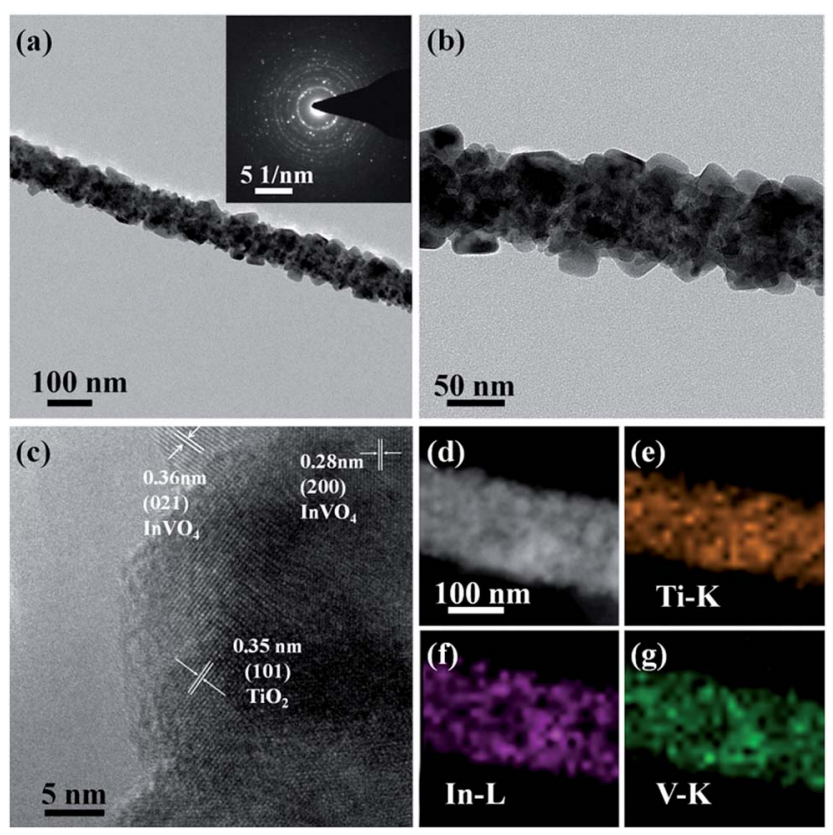

Fig. 2 (a and b) TEM images and (c) a high magnification TEM (HRTEM) image of the $\mathrm{TiO}_{2} / \mathrm{InVO}_{4} \mathrm{NFs}(\mathrm{Ti} / \mathrm{In}=4: 1) ;(\mathrm{d}-\mathrm{g}) \mathrm{STEM}$ image of the $\mathrm{TiO}_{2} / \mathrm{InVO}_{4} \mathrm{NFs}(\mathrm{Ti} / \mathrm{In}=4: 1)$ (d), and the corresponding EDX elemental maps of $\mathrm{Ti}(\mathrm{e})$, In (f), and $\mathrm{V}(\mathrm{g})$, respectively. 


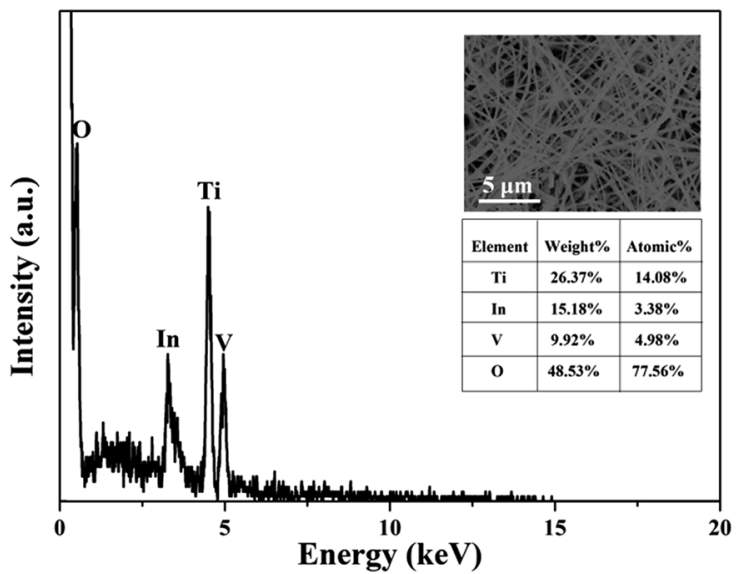

Fig. 3 EDS pattern of the $\mathrm{TiO}_{2} / \operatorname{lnVO}_{4} \mathrm{NFs}(\mathrm{Ti} / \mathrm{ln}=4: 1)$

$14.08 \%$, 3.38\%, and $4.98 \%$, respectively, implying the molar ratio of $\mathrm{Ti} / \mathrm{In}$ is about 4.2 , which is in agreement with the set value of the $\mathrm{Ti} / \mathrm{In}$ molar ratio in the electrospinning process. Furthermore, XPS measurements were employed and the results are displayed in Fig. 4. Fig. 4(a) shows the holistic survey spectrum of the $\mathrm{TiO}_{2} / \mathrm{InVO}_{4}$ NFs, in which Ti, In, V, and $\mathrm{O}$ are detected. In addition, the $\mathrm{Ti} 2 \mathrm{p}$, In $3 \mathrm{~d}$, and $\mathrm{V} 2 \mathrm{p}$ core-level spectra of the $\mathrm{TiO}_{2} / \mathrm{InVO}_{4}$ NFs are shown in Fig. 4(b-d). The peaks at $444.5 \mathrm{eV}$ and $452.0 \mathrm{eV}$ in the In $3 \mathrm{~d}$ core-level spectrum, as shown in Fig. $3($ b), correspond to In $3 d 3 / 2$ and In $3 d 5 / 2$ for $\mathrm{In}^{3+}$ species, respectively. ${ }^{31}$ As shown in Fig. $4(\mathrm{c})$, the $\mathrm{V} 2 \mathrm{p}$ peaks are located at $517.1 \mathrm{eV}$ and $524.6 \mathrm{eV}$, which can be ascribed to $\mathrm{V}^{5+} \cdot{ }^{32}$ From the Ti $2 \mathrm{p}$ core-level spectrum in Fig. 4(d), two clearly evident peaks centered at 463.8 and $458.2 \mathrm{eV}$ can be assigned to Ti 2p1/2 and $\mathrm{Ti} 2 \mathrm{p} 3 / 2$, respectively, which belong to the $\mathrm{Ti}^{4+}$ elemental chemical state of $\mathrm{TiO}_{2} \cdot{ }^{33}$ It can be therefore concluded that the $\mathrm{TiO}_{2} / \mathrm{InVO}_{4}$ NFs have been fabricated successfully.

We then investigated the photocatalytic performance of $\mathrm{TiO}_{2}$ NFs and $\mathrm{TiO}_{2} / \mathrm{InVO}_{4}$ NFs with different $\mathrm{Ti} / \mathrm{In}$ molar ratios
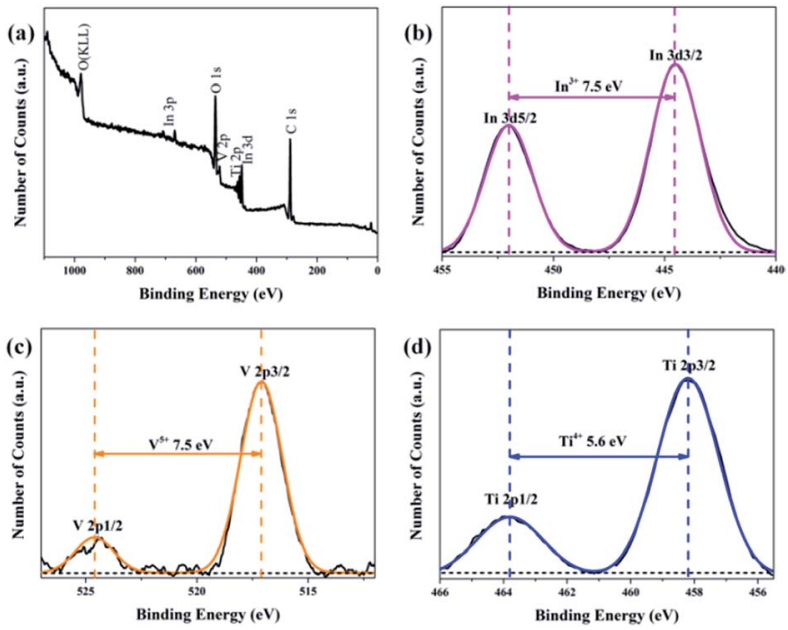

Fig. 4 (a) XPS survey spectrum of the $\mathrm{TiO}_{2} / \operatorname{lnVO} \mathrm{NFs}_{4}(\mathrm{Ti} / \mathrm{In}=4: 1)$, and $(b-d)$ high resolution XPS spectra of the In $3 d, V 2 p$, and Ti $2 p$ core-level binding energies, respectively. toward the photodegradation process of RhB solution. As shown in Fig. 5(a), after adding $50 \mathrm{mg} \mathrm{TiO} / \mathrm{InVO}_{4} \mathrm{NFs}(\mathrm{Ti} / \mathrm{In}=$ $4: 1$ ) as a photocatalyst into RhB solution, the $\lambda_{\max }$ intensity of the absorption spectral changes of the RhB solution is significantly decreased with irradiation time. Fig. 5(b) presents the corresponding concentration change in the RhB solution when using different samples as photocatalysts under visible-light irradiation. It is obviously that after $80 \mathrm{~min}$ of visible-light irradiation, only $18 \%$ and $32 \%$ of $\mathrm{RhB}$ molecules are decomposed by the $\mathrm{TiO}_{2}$ NFs and standard P25, respectively, which can be assigned to their poor visible-light absorption and short photogenerated charge lifetime. As for the $\mathrm{TiO}_{2} / \mathrm{InVO}_{4} \mathrm{NFs}$, at least $80 \%$ of RhB molecules are effectively decomposed, indicating that the $\mathrm{TiO}_{2} / \mathrm{InVO}_{4}$ NFs achieve an outstanding enhanced visible photocatalytic performance, better than that of pure $\mathrm{TiO}_{2}$ NFs. Moreover, while using the $\mathrm{TiO}_{2} / \mathrm{InVO}_{4} \mathrm{NFs}$ with a Ti/In molar ratio of $4: 1$ as photocatalysts, about $95 \%$ of RhB molecules are decomposed. In addition, as shown in Fig. 5(c), the degradation rates obtained over the $\mathrm{TiO}_{2} / \mathrm{InVO}_{4}$ NFs ( Ti/In = $4: 1), \mathrm{TiO}_{2} / \mathrm{InVO}_{4}$ NFs (Ti/In = $\left.2: 1\right), \mathrm{TiO}_{2} / \mathrm{InVO}_{4}$ NFs $(\mathrm{Ti} / \mathrm{In}=8: 1), \mathrm{P} 25$, and $\mathrm{TiO}_{2}$ NFs are 0.03632, 0.0238, $0.01756,0.0033$, and 0.00244 , respectively. Furthermore, the photocatalytic performance of $\mathrm{TiO}_{2} / \mathrm{InVO}_{4} \mathrm{NFs}$ was enhanced with the increasing amount of $\mathrm{InVO}_{4}$ and reached the best photocatalytic activity at a Ti/In molar ratio of $4: 1$. The increasing surface area with the increase in the amount of $\mathrm{InVO}_{4}$ is beneficial for the improvement of the photocatalytic activity, which is in agreement with the morphology results and dark absorption during the photocatalysis process. However, with a further increase of $\mathrm{InVO}_{4}$ amount, the epitaxial growth of $\mathrm{InVO}_{4}$ would undermine the uniformity of the nanoheterostructures and suppress the separation of the electronhole pairs, so superabundant $\mathrm{InVO}_{4}$ is conversely unfavorable for improving photocatalytic activity. So, the $\mathrm{TiO}_{2} / \mathrm{InVO}_{4} \mathrm{NFs}$
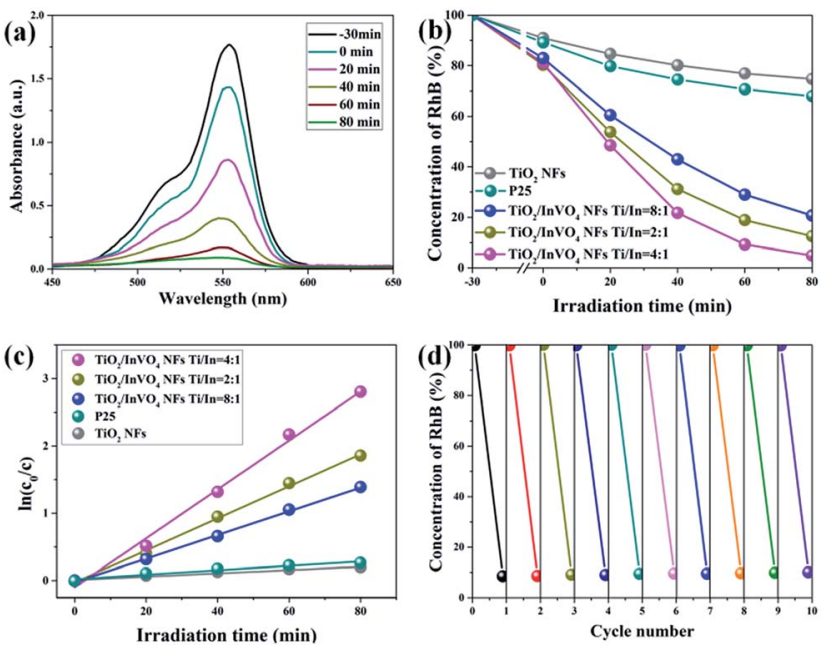

Fig. 5 (a) Absorption spectral changes of RhB solution in the presence of $\mathrm{TiO}_{2} / \mathrm{InVO}_{4} \mathrm{NFs}(\mathrm{Ti} / \mathrm{ln}=4: 1$ ) under visible-light irradiation. (b) Comparison of the visible-light photocatalytic degradation of $\mathrm{RhB}$ and (c) the photodegradation rates in the presence of $\mathrm{TiO}_{2}$ and $\mathrm{TiO}_{2} / \mathrm{InVO}_{4}$ NFs. (d) Cycling tests of the photocatalytic activity of the $\mathrm{TiO}_{2} / \mathrm{InVO}_{4}$ $\mathrm{NFs}(\mathrm{Ti} / \mathrm{ln}=4: 1)$. 
with a Ti/In molar ratio of 4:1 may exhibit outstanding synergistic effects with an appropriate surface area and nanoheterostructure, thereby allowing them to displaying the highest photocatalytic activity. Hence, we mainly conducted indepth causal discussions on the enhanced visible-light photocatalytic performance of $\mathrm{TiO}_{2} / \mathrm{InVO}_{4} \mathrm{NFs}$ with a Ti/In molar ratio of $4: 1$ in the following research. Based on further practical application, the stability of the photocatalyst is a very significant factor for recycling. Herein, ten cycles of the photodegradation behaviour of RhB are shown in Fig. 5(d) in order to evaluate the photocatalytic stability of the $\mathrm{TiO}_{2} / \mathrm{InVO}_{4} \mathrm{NFs}$. After each cycle of the photocatalysis reaction process, it can seen that there is only negligible reduction in the photocatalytic activity, indicating the excellent reusability and stability of the $\mathrm{TiO}_{2} / \mathrm{InVO}_{4}$ NFs. In a word, $\mathrm{TiO}_{2} / \mathrm{InVO}_{4}$ NFs exert an outstanding stability, and a much enhanced visible-light photocatalytic activity compared with pure $\mathrm{TiO}_{2} \mathrm{NFs}$.

Based on the excellent results, we have mainly conducted indepth causal discussions on three aspects of the enhanced visible-light photocatalytic performance of the $\mathrm{TiO}_{2} / \mathrm{InVO}_{4} \mathrm{NFs}$. Firstly, it is well known that surface area is an important factor for photocatalysis. ${ }^{34}$ Hence, as shown in Fig. 6(a), we employed a BET adsorption/desorption of nitrogen gas method to evaluate the specific surface area of the $\mathrm{TiO}_{2} \mathrm{NFs}$ and $\mathrm{TiO}_{2} / \mathrm{InVO}_{4} \mathrm{NFs}$. The BET surface area of the $\mathrm{TiO}_{2} / \mathrm{InVO}_{4} \mathrm{NFs}$, calculated from the nitrogen isotherm curve, is $30.5 \mathrm{~m}^{2} \mathrm{~g}^{-1}$, which is about two times higher than that of the $\mathrm{TiO}_{2} \mathrm{NFs}\left(16.8 \mathrm{~m}^{2} \mathrm{~g}^{-1}\right)$. Obviously, the increased surface area of the $\mathrm{TiO}_{2} / \mathrm{InVO}_{4} \mathrm{NFs}$ would provide a larger available active area for the photocatalytic reaction. Accordingly, the increasing surface area of the $\mathrm{TiO}_{2} / \mathrm{InVO}_{4} \mathrm{NFs}$ would efficiently promote photocatalytic activity.

In particular, optical absorption characteristics have a direct influence on the photocatalytic activity of semiconductors. Herein, we employed UV-Vis absorbance spectroscopy to attest whether $\mathrm{TiO}_{2} / \mathrm{InVO}_{4}$ NFs have a wider light absorption range for visible light compared with $\mathrm{TiO}_{2} \mathrm{NFs}$, and the results are shown in Fig. 6(b). $\mathrm{TiO}_{2}$ NFs present an evident absorption edge located at $400 \mathrm{~nm}$, derived from the intrinsic energy gap of $\mathrm{TiO}_{2}$. The UV-Vis spectra of the $\mathrm{TiO}_{2} / \mathrm{InVO}_{4}$ NFs reveal a wide visible-light absorption band around 400-650 nm, which contributed to the introduction of the narrow band gap $\mathrm{InVO}_{4}$ semiconductor. This effectual change of the absorption spectra indicates that the $\mathrm{TiO}_{2} / \mathrm{InVO}_{4}$ NFs have broader spectral harvesting, ultimately leading to the improvement of the visiblelight photocatalytic activity.
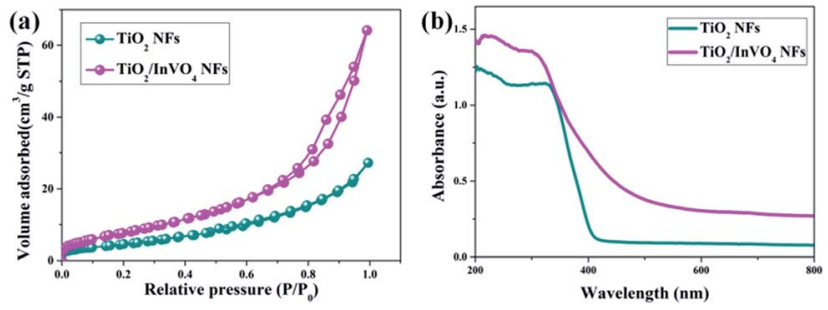

Fig. 6 (a) $\mathrm{N}_{2}$ adsorption-desorption isotherms and (b) UV-Vis absorbance spectra of the $\mathrm{TiO}_{2} \mathrm{NFs}$ and $\mathrm{TiO}_{2} / \mathrm{InVO}_{4} \mathrm{NFs}$.
It is fairly well acknowledged that a lower PL emission intensity of the samples under the same laser irradiation intensity implies less electron-hole recombination. ${ }^{35}$ Herein, we employed steady-state and time-resolved transient PL spectroscopy to characterize the capability of electron-hole pair separation in the nanofibers. As shown in Fig. 7(a), in the $\mathrm{TiO}_{2}$ NF PL spectrum, the strong emission band at around 550-850 $\mathrm{nm}$ is mainly attributed to deep and shallow trap centers of oxygen defects and excitons. ${ }^{36}$ However, the $\mathrm{TiO}_{2} /$ InVO $_{4} \mathrm{NFs}$ have a substantially lower PL intensity than the $\mathrm{TiO}_{2}$ NFs, which implies that recombination of the photogenerated electron-hole pairs in the $\mathrm{TiO}_{2} / \mathrm{InVO}_{4} \mathrm{NFs}$ is effectively suppressed.

Time-resolved photoluminescence (TRPL) is an effective method employed to extract the carrier lifetime $(\tau)$, which can directly indicate various radiative and non-radiative loss channels responsible for photogenerated carrier recombination. ${ }^{37}$ To further verify the nanoheterojunction's functions of electronhole separation and carrier transfer in the $\mathrm{TiO}_{2} / \mathrm{InVO}_{4} \mathrm{NFs}$, TRPL was employed at room temperature to explore the dynamics of the photogenerated charge. The transient emission spectra for the $\mathrm{TiO}_{2}$ NFs and $\mathrm{TiO}_{2} / \mathrm{InVO}_{4}$ NFs are shown in Fig. 7(b and c). The PL decay profile is fitted using a multiexponential function as follows: ${ }^{38,39}$

$$
I_{\mathrm{t}}=\sum_{i=1}^{n} A_{i} \exp \left(-t / \tau_{i}\right)
$$

where $I_{\mathrm{t}}$ is intensity, $A_{i}$ is the relative magnitude of the $i$ th decay, and $\tau_{i}$ is the $i$ th decay time. It can be deduced that the $\mathrm{TiO}_{2} /$ InVO $_{4}$ NFs yield the longest decay time $\left(\tau_{1}=2.047 \mathrm{~ns}, A_{1}=\right.$ $0.1475 ; \tau_{2}=27.862 \mathrm{~ns}, A_{2}=0.0368$ ) compared with the $\mathrm{TiO}_{2} \mathrm{NFs}$ $\left(\tau_{1}=1.339 \mathrm{~ns}, A_{1}=0.2172 ; \tau_{2}=23.686 \mathrm{~ns}, A_{2}=0.212\right)$. Furthermore, the fast factor $\left(\tau_{1}\right)$ commonly corresponds to the non-radiative relaxation process, owing to oxide defects, ${ }^{40}$ and the slow factor $\left(\tau_{2}\right)$ is attributed to the radiative pathway, related to the recombination of photogenerated electron-hole pairs. ${ }^{41}$ Furthermore, the average lifetimes $\left(\tau_{\text {ave }}\right)$ can be deduced through the following equation for a general comparison of the carrier lifetime: ${ }^{42}$

$$
\tau_{\text {ave }}=f_{1} \tau_{1}+f_{2} \tau=\frac{A_{1} \tau_{2}^{2}+A_{2} \tau_{2}^{2}}{A_{1} \tau_{1}+A_{2} \tau_{2}}
$$

The values for the average time calculated based on twoexponential decays for the $\mathrm{TiO}_{2} / \mathrm{InVO}_{4} \mathrm{NFs}$ and $\mathrm{TiO}_{2}$ NFs are $22 \mathrm{~ns}$ and $15 \mathrm{~ns}$, respectively. In order to compare the separation efficiency of the $\mathrm{TiO}_{2} / \mathrm{InVO}_{4}$ heterostructures, we list the carrier lifetimes of different $\mathrm{TiO}_{2}$-based heterostructures reported previously in Table 1 , and it is obvious that the $\mathrm{TiO}_{2} / \mathrm{InVO}_{4} \mathrm{NFs}$ with tailored heterostructure features exhibit longer carrier lifetimes than $\mathrm{TiO}_{2} / \mathrm{SiO}_{2}, \mathrm{TiO}_{2} / \mathrm{In}_{2} \mathrm{~S}_{3}$, and $\mathrm{TiO}_{2} / \mathrm{MoS}_{2}$, implying that this kind of heterostructure prepared by electrospinning can provide ample heterojunction interfaces for more separation channels for photogenerated electron-hole pairs.

To better understand the charge separation in $\mathrm{TiO}_{2} / \mathrm{InVO}_{4}$ NFs, a schematic illustration of the efficient separation and 

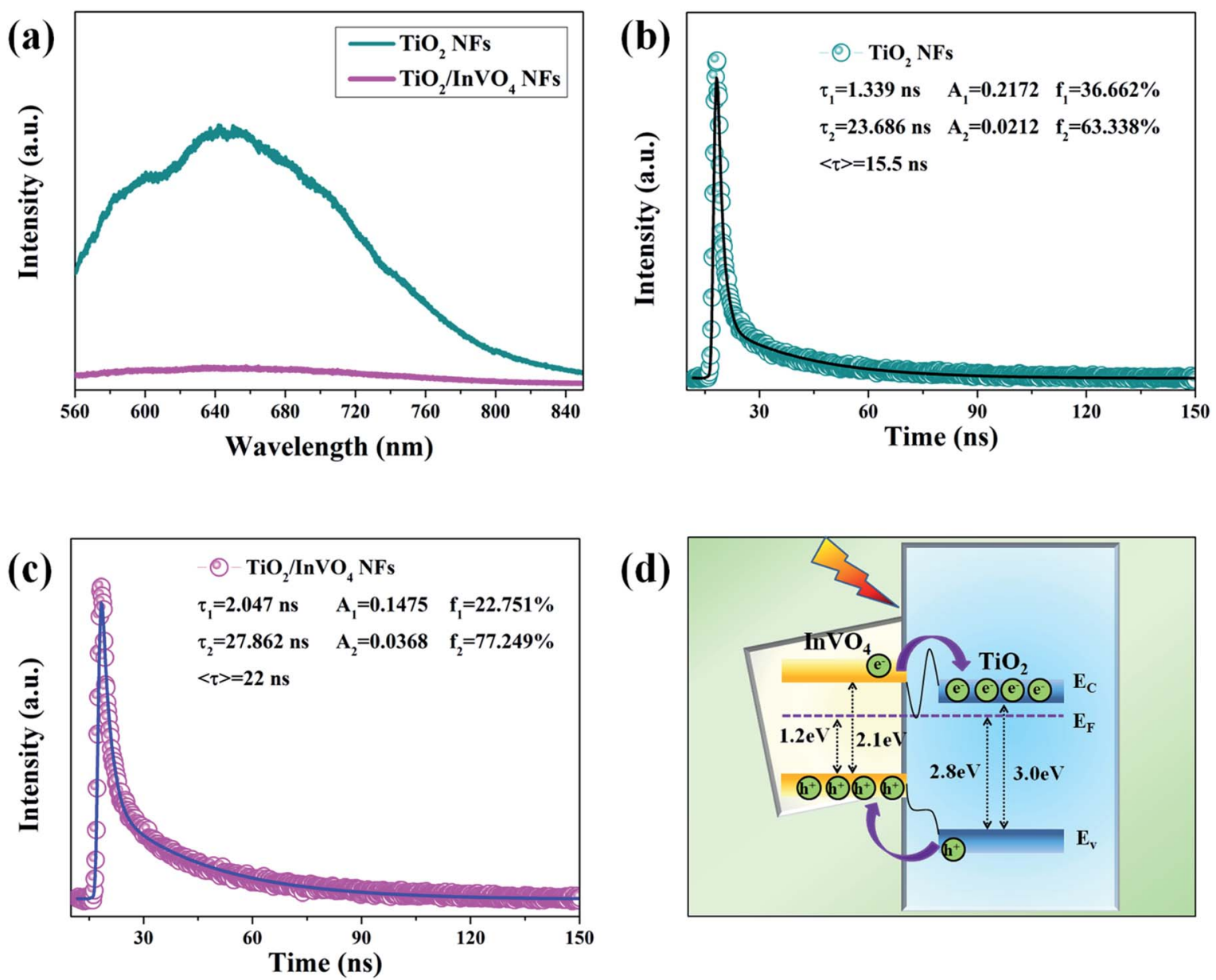

Fig. 7 (a) Steady-state PL spectra of $\mathrm{TiO}_{2} \mathrm{NFs}$ and $\mathrm{TiO}_{2} / \mathrm{InVO}_{4} \mathrm{NFs}(\mathrm{Ti} / \mathrm{In}=4: 1$ ). (b and c) Time-resolved transient PL decay of TiO 2 NFs and $\mathrm{TiO}_{2} / \mathrm{InVO}_{4} \mathrm{NFs}(\mathrm{Ti} / \mathrm{In}=4: 1)$, respectively. (d) Schematic illustration of energy band matching and the proposed mechanism of charge carrier transition for $\mathrm{TiO}_{2} / \mathrm{InVO}_{4}$ nanoheterojunctions under visible-light irradiation, including conduction bands $\left(E_{\mathrm{C}}\right)$, valence bands $\left(E_{\mathrm{V}}\right)$, and Fermi levels $\left(E_{\mathrm{F}}\right)$.

transport of photogenerated charge in the $\mathrm{TiO}_{2} / \mathrm{InVO}_{4} \mathrm{NFs}$ is represented in Fig. 7(d). The standard literature energy levels of $\mathrm{TiO}_{2}$ and $\mathrm{InVO}_{4}$ (conduction bands of $-4.0 \mathrm{eV}$ and $-3.6 \mathrm{eV}$, valance bands of $-7.0 \mathrm{eV}$ and $-5.7 \mathrm{eV}$, and Fermi levels of $-4.2 \mathrm{eV}$ and $-4.5 \mathrm{eV}$, vs. the vacuum level, respectively) were employed for the energy band matching analysis here. ${ }^{45}$ The matching energy band between $\mathrm{InVO}_{4}$ and $\mathrm{TiO}_{2}$ is shown in Fig. 6(d), when the nanoheterostructures are formed, the Fermi energy bands of $\mathrm{TiO}_{2}$ and $\mathrm{InVO}_{4}$ are at the same level, which thus leads both the conduction band $\left(E_{\mathrm{C}}\right)$ and valence band $\left(E_{\mathrm{V}}\right)$ of $\mathrm{InVO}_{4}$ to locate above those of $\mathrm{TiO}_{2}$. Under visible-light irradiation, $\mathrm{InVO}_{4}$ in the $\mathrm{TiO}_{2} / \mathrm{InVO}_{4} \mathrm{NFs}$ is photoexcited to

Table 1 Carrier lifetimes of different $\mathrm{TiO}_{2}$-based heterostructures

\begin{tabular}{lllll}
$\begin{array}{l}\text { Heterostructure } \\
\text { composites }\end{array}$ & $\begin{array}{l}\mathrm{TiO}_{2} / \mathrm{InVO}_{4} \\
\mathrm{NFs}\end{array}$ & $\begin{array}{l}\mathrm{TiO}_{2} / \mathrm{SiO}_{2} \\
\mathrm{film}^{43}\end{array}$ & $\begin{array}{l}\mathrm{TiO}_{2} / \mathrm{In}_{2} \mathrm{~S}_{3} \\
\text { nanobelts }\end{array}$ & $\begin{array}{l}\mathrm{TiO}_{2} / \mathrm{MoS}_{2} \\
\text { nanocomposite }\end{array}$ \\
\hline$\tau_{1}(\mathrm{~ns})$ & 2.047 & 0.0824 & 0.67 & - \\
$\tau_{2}(\mathrm{~ns})$ & 27.862 & 0.898 & 4.64 & - \\
$T_{\text {ave }}(\mathrm{ns})$ & 22 & - & - & 9.49
\end{tabular}

produce electron-hole pairs, and owing to the incomparable nanoheterojunction structure formed at the interfaces of $\mathrm{TiO}_{2}$ and $\mathrm{InVO}_{4}$, the photogenerated electrons can facilely transport to the $E_{\mathrm{C}}$ of $\mathrm{TiO}_{2}$. Hereby, numerous photogenerated electrons transport from the $E_{\mathrm{C}}$ of $\mathrm{InVO}_{4}$ to that of $\mathrm{TiO}_{2}$, and photogenerated holes concentrate on the $E_{\mathrm{V}}$ of $\mathrm{InVO}_{4}$. In this way, the separation of the photogenerated charge can be efficiently facilitated, thereby prolonging the carrier lifetimes and resulting in the enhanced photocatalytic activity of the $\mathrm{TiO}_{2} / \mathrm{InVO}_{4}$ NFs under visible-light irradiation.

\section{Conclusions}

In summary, $\mathrm{TiO}_{2} / \mathrm{InVO}_{4} \mathrm{NFs}$ were successfully fabricated by a facile one-pot electrospinning method. The $\mathrm{TiO}_{2} / \mathrm{InVO}_{4} \mathrm{NFs}$ showed a significantly enhanced photocatalytic performance; almost $95 \%$ of RhB molecules were decomposed within $80 \mathrm{~min}$ by the $\mathrm{TiO}_{2} / \mathrm{InVO}_{4} \mathrm{NFs}(\mathrm{Ti} / \mathrm{In}=4: 1)$, but only $18 \%$ of $\mathrm{RhB}$ molecules were decomposed by pure $\mathrm{TiO}_{2} \mathrm{NFs}$. Moreover, the time-resolved transient PL spectra reveal that the $\mathrm{TiO}_{2} / \mathrm{InVO}_{4}$ NFs exhibit a prolonged average carrier lifetime of $22 \mathrm{~ns}$, more 
than that of the $\mathrm{TiO}_{2} \mathrm{NFs}$, which can promote photogenerated carrier separation. Accordingly, the resulting $\mathrm{TiO}_{2} / \mathrm{InVO}_{4} \mathrm{NFs}$ display excellent visible-light photocatalytic performance, owing to their prominent visible-light harvesting and electronhole separation properties. It is indisputable that $\mathrm{TiO}_{2} / \mathrm{InVO}_{4}$ NFs may shed new light on highly efficient visible-light nanoheterostructured photocatalysts with longer carrier lifetimes.

\section{Conflicts of interest}

There are no conflicts to declare.

\section{Acknowledgements}

This work was supported by the National Natural Science Foundation of China (No. 11704354) and the Hunan Provincial Innovation Foundation for Postgraduate (No. $8443 \mid 431000203431000203)$.

\section{Notes and references}

1 D. M. Schultz and T. P. Yoon, Science, 2014, 343, 1239176.

2 K. Nakata, B. Liu, Y. Goto, T. Ochiai, M. Sakai, H. Sakai, T. Murakami, M. Abe and A. Fujishima, Chem. Lett., 2011, 40, 1161-1162.

3 J. Ran, J. Zhang, J. Yu, M. Jaroniec and S. Z. Qiao, Chem. Soc. Rev., 2014, 43, 7787-7812.

4 A. Fujishima and K. Honda, Nature, 1972, 238, 37.

5 Y. Bai, I. Mora-Sero, F. D. Angelis, J. Bisquert and P. Wang, Chem. Rev., 2014, 114, 10095-10130.

6 S. G. Kumar and L. G. Devi, J. Phys. Chem. A, 2011, 115, 13211-13241.

7 C. P. Sajan, S. Wageh, A. A. Al-Ghamdi, J. Yu and S. Cao, Nano Res., 2016, 9, 3-27.

8 J. Hensel, G. Wang, Y. Li and J. Z. Zhang, Nano Lett., 2010, 10, 478-483.

9 R. Asahi, T. Morikawa, T. Ohwaki, K. Aoki and Y. Taga, Science, 2001, 293, 269-271.

10 T. Huang, S. Mao, J. Yu, Z. Wen, G. Lu and J. Chen, RSC Adv., 2013, 3, 16657-16664.

11 W. He, Z. Fang, K. Zhang, X. Li, D. Ji, X. Jiang, C. Qiu and K. Guo, RSC Adv., 2015, 5, 54853-54860.

12 X. Chen, L. Liu, Y. Y. Peter and S. S. Mao, Science, 2011, 331, 746-750.

13 Y. Shi, D. Yang, Y. Li, J. Qu and Z. Z. Yu, Appl. Surf. Sci., 2017, 426, 622-629.

14 X. Zhang, Z. Shen, C. Cheng, L. Shi, R. Cheng and J. Dong, RSC Adv., 2017, 7, 52172-52179.

15 C. Cheng, J. Shi, Y. Hu and L. Guo, Nanotechnology, 2017, 28, 164002.

16 H. Zhang, F. Liu, H. Wu, X. Cao, J. Sun and W. Lei, RSC Adv., 2017, 7, 40327-40333.

17 M. N. Ha, F. Zhu, Z. Liu, L. Wang, L. Liu, G. Lu and Z. Zhao, RSC Adv., 2016, 6, 21111-21118.

18 H. Wang, L. Zhang, Z. Chen, J. Hu, S. Li, Z. Wang, J. Liu and X. Wang, Chem. Soc. Rev., 2014, 43, 5234-5244.

19 C. Cheng, W. Ren and H. Zhang, Nano Energy, 2014, 5, 132-138.
20 P. G. Ramos, E. Flores, L. A. Sánchez, R. J. Candal, M. Hojamberdiev, W. Estrada and J. Rodriguez, Appl. Surf. Sci., 2017, 426, 844-851.

21 F. Tian, D. Hou, F. Hu, K. Xie, X. Qiao and D. Li, Appl. Surf. Sci., 2017, 391(Part B), 295-302.

22 X. Ren, X. Qi, Y. Shen, S. Xiao, G. Xu, Z. Zhang, Z. Huang and J. Zhong, J. Phys. D: Appl. Phys., 2016, 49, 315304.

23 S. P. Adhikari, G. P. Awasthi, J. Lee, C. H. Park and C. S. Kim, RSC Adv., 2016, 6, 55079-55091.

24 F. Xu, J. Zhang, B. Zhu, J. Yu and J. Xu, Appl. Catal., B, 2018, 230, 194-202.

25 X. Zhang, Catal. Lett., 2014, 144, 1253-1257.

26 Y. Yan, X. Liu, W. Fan, P. Lv and W. Shi, Chem. Eng. J., 2012, 200-202, 310-316.

27 J. Shen, H. Yang, Y. Feng, Q. Cai and Q. Shen, Solid State Sci., 2014, 32, 8-12.

28 I. A. Perales-Martínez, V. Rodríguez-González, S. W. Lee and S. Obregón, J. Photochem. Photobiol., A, 2015, 299, 152-158.

29 Y. Min, K. Zhang, Y. C. Chen and Y. G. Zhang, Ultrason. Sonochem., 2012, 19, 883-889.

30 L. Ge, M. Xu and H. Fang, Mater. Lett., 2007, 61, 63-66.

31 F. Guo, W. Shi, X. Lin, X. Yan, Y. Guo and G. Che, Sep. Purif. Technol., 2015, 141, 246-255.

32 A. Chakrabarti, K. Hermann, R. Druzinic, M. Witko, F. Wagner and M. Petersen, Phys. Rev. B: Condens. Matter Mater. Phys., 1999, 59, 10583-10590.

33 H. Li, Y. Wang, G. Chen, Y. Sang, H. Jiang, J. He, X. Li and H. Liu, Nanoscale, 2016, 8, 6101-6109.

34 G. Tian, Y. Chen, W. Zhou, K. Pan, C. Tian, X. Huang and H. Fu, CrystEngComm, 2011, 13, 2994.

35 Z. Zhang, C. Shao, X. Li, L. Zhang, H. Xue, C. Wang and Y. Liu, J. Phys. Chem. C, 2010, 114, 7920-7925.

36 K. Iijima, M. Goto, S. Enomoto, H. Kunugita, K. Ema, M. Tsukamoto, N. Ichikawa and H. Sakama, J. Lumin., 2008, 128, 911-913.

37 H. H. Wang, Q. Chen, H. Zhou, L. Song, Z. S. Louis, N. D. Marco, Y. Fang, P. Sun, T. B. Song, H. Chen and Y. Yang, J. Mater. Chem. A, 2015, 3, 9108-9115.

38 J. L. Wu, F. C. Chen, Y. S. Hsiao, F. C. Chien, P. L. Chen, C. H. Kuo, M. H. Huang and C. S. Hsu, ACS Nano, 2011, 5, 959-967.

39 S. W. Cao, X. F. Liu, Y. P. Yuan, Z. Y. Zhang, Y. S. Liao, J. Fang, S. C. J. Loo, T. C. Sum and C. Xue, Appl. Catal., B, 2014, 147, 940-946.

40 Y. Li, T. Li, J. Tian, X. Wang and H. Cui, Part. Part. Syst. Charact., 2017, 34, 1700127.

41 X. Zeng and W. Qin, Mater. Lett., 2016, 182, 347.

42 B. R. Masters, J. Biomed. Opt., 2008, 13, 029901.

43 K. Miyashita, S. Kuroda, S. Tajima, K. Takehira, S. Tobita and H. Kubota, Chem. Phys. Lett., 2003, 369, 225-231.

44 H. S. Han, K. M. Kim, C. W. Lee, C. S. Lee, R. C. Pawar, J. L. Jones, Y. R. Hong, J. H. Ryu, T. Song, S. H. Kang, H. Choi and S. Mhin, Phys. Chem. Chem. Phys., 2017, 19, 28207-28215.

45 G. Xiao, X. Wang, D. Li and X. Fu, J. Photochem. Photobiol., A, 2008, 193, 213-221. 